\title{
Factors Associated with Aspiration Risk among Geriatric Patients with
}

\section{Dysphagia}

\author{
Asmaa Mahmoud Ali Ibrahim, Demonstrator \\ Gerontological Nursing, Faculty of Nursing, Alexandria University \\ Moshera Mostafa El-Geneidy, Professor \\ Gerontological Nursing, Faculty of Nursing, Alexandria University \\ Rasha Ahmed Fouad, Professor \\ Gerontological Nursing, Faculty of Nursing, Alexandria University
}

\author{
Abeer Abd El Galeel Abd El Moneam, Lecturer \\ Gerontological Nursing, Faculty of Nursing, Alexandria University
}

\begin{abstract}
Dysphagia is considered a serious problem affecting geriatric patients because of the increased risk of aspiration. Dysphagia and risk for aspiration is a geriatric syndrome that should be screened early and treated in all hospital admitted geriatric patients in order to reduce morbidity and length of hospital stay. Objective: Identify the factors associated with aspiration risk among geriatric patients with dysphagia. Setting: The study was carried out in the Medical Units of the Main University Hospital, Alexandria, Egypt. Subjects: The study included 100 geriatric patients with dysphagia admitted to the selected units and fulfilling the following criteria; age 60 years and more, with no contraindication for oral feeding, able to maintain sitting position, able to communicate and available at the time of data collection. Tools: Four tools were used for data collection: 1) Gugging Swallowing Screen (GUSS), 2) Socio-demographic and clinical data of geriatric patients with dysphagia structured interview schedule, 3) Factors associated with aspiration risk among geriatric patients with dysphagia structured interview schedule, 4) Barthel Index. Results: Severe dysphagia with a high risk of aspiration was observed in $37.0 \%$ of the study geriatric patients, while moderate dysphagia with a risk of aspiration in $27.0 \%$ and those who had slight dysphagia with a low risk of aspiration in $36.0 \%$.The severity of dysphagia and aspiration risk is affected significantly by living arrangement, level of dependency, receiving chemotherapy treatment, mouth dryness and weak tongue movement as a side effects of medication. Conclusion: The severity of dysphagia and aspiration risk were affected by several factors as filing mouth with foods, feeling tired and fatigued during meals. Moreover, dysphagia and aspiration risk were associated with illiteracy and specific medical diagnosis as hypertension, heart failure and leukemia. Recommendations: Comprehensive assessment of geriatric patients for dysphagia and aspiration risk should be a routine and basic procedure of the gerontological nurse in order to identify early those at risk and implement appropriate nursing interventions to prevent complications.
\end{abstract}

Keywords: Dysphagia; Geriatric patients; Aspiration risk; factors; Gerontological nurse.

\section{Introduction}

Dysphagia is the subjective sensation of difficult swallowing. It is not a disease rather a symptom of an underlying disorder $^{(1-3)}$. It is a common and important problem affecting geriatric patients. It is considered a serious problem because of the increased risk of aspiration ${ }^{(4-6)}$. Aspiration refers to the inhalation of oropharyngeal or gastric contents into the larynx and lower respiratory $\operatorname{tract}^{(7)}$. Aspirate can include food, saliva and gastric content. Symptoms of aspiration include, a sudden appearance of severe coughing or cyanosis associated with eating or drinking and voice changes. Some geriatric patients who aspirate do not have any sign or symptom. This is called silent aspiration. It is found in more than $50 \%$ of older adults who aspirate ${ }^{(8,9)}$. 
Dysphagia and aspiration are associated with high morbidity and mortality. Furthermore, dysphagia and risk of aspiration can lead to depression and deterioration in the quality of life ${ }^{(10-12)}$.

The reported prevalence of dysphagia in Taiwan (2005) reached over 50\% among hospitalized geriatric patients with acute illnesses such as stroke ${ }^{(13)}$. According to the World Gastroenterology Organization Global Guidelines 2007, the incidence of dysphagia among geriatric patients in acute care centers was about $33 \%$ and in nursing homes about $30-40 \%{ }^{(14)}$. Different studies in USA showed that dysphagia rates among geriatric patients in hospital increased from $20 \%$ in 2002 to $70 \%$ in $2007^{(15)}$.

In Australia (2011), the prevalence of dysphagia among older adults in the community was between 7 and $22 \%$ and about 40 to $50 \%$ among older people in long-term care facilities ${ }^{(6)}$. While in2015 the prevalence of oropharyngeal dysphagia was reported to be $27.2 \%$ among independently living elderly and 47.4 \% among hospitalized geriatric patients ${ }^{(16,17)}$. In Turkey (2016), the Oropharyngeal dysphagia is a prevalent geriatric syndrome. It affects up to $78 \%$ of nursing home residents, $31 \%-71 \%$ of hospitalized geriatric patients, and $15 \%-23 \%$ of community-dwelling older adults ${ }^{(18)}$. In Egypt, a study carried out in Alexandria in 2006 revealed that the prevalence of dysphagia among hospitalized geriatric patients with stroke was $45 \%{ }^{(19)}$, while in Sohag, Egypt (2014) the reported prevalence of dysphagia among hospitalized geriatric patients was $14.7 \%^{(20)}$.

Dysphagia and risk for aspiration are caused by a number of problems such as gastrointestinal reflux disease, problems in the stomach with digestion and esophageal cancer, neurological diseases such as stroke, Parkinson's disease and Alzheimer's disease. Moreover, heart failure, diabetes mellitus, over use of sedative and psychotropic medications and general frailty put geriatric patients at greater risk for swallowing impairment. Also, People with altered level of consciousness or severe fatigue are at risk $^{(21,22)}$. Other risk factors for aspiration among geriatric patients are poor eating habits such as swallowing food without chewing, talking while eating, fast eating and drinking while mouth full with food ${ }^{(22,23)}$.

The gerontological nurse, as a member of the multidisciplinary team, and being in direct contact for 24hours daily with geriatric patients in hospital play an important role in the assessment, early identification, management and prevention of complications related to dysphagia and to identify the factors associated with aspiration risk. This can be achieved through using dysphagia screening tools in order to initiate early nursing interventions that may prevent further complications such as aspiration $^{(9,24,25)}$.

\section{Aim of the Study}

This study aimed to identify the factors associated with aspiration risk among geriatric patients with dysphagia.

\section{Research Question}

What are the factors associated with aspiration risk among geriatric patients with dysphagia?

\section{Materials and Method}

\section{Materials}

Design: This study followed a descriptive research design.

Setting: The study was carried out in the Medical Units of the Alexandria Main University Hospital, namely; cardiovascular diseases, geriatric medicine, gastrointestinal diseases, liver, gallbladder and pancreatic diseases, rheumatoid, autoimmune diseases and hematology diseases. These units were selected based on reviewing the hospital statistical records of these units during the year 2016 which revealed that the average monthly attendance of geriatric patients in these units ranged from 80 to 85 geriatric patients $^{(26)}$. 
Subjects: The study included 100 geriatric patients with dysphagia admitted to the selected units and fulfilling the following criteria: age 60 years and more, with no contraindication for oral feeding, able to maintain sitting position,able to communicate, and available at the time of data collection.

The number of the study subjects was estimated using the Epi info 7.0 Program based on the following parameters; Population size $=250$ over three months, Expected frequency $=50 \%$, Acceptable error $=10 \%$, Confidence co efficient $=99 \%$, the minimal Sample size was 80 .

Tools: Four tools were used for data collection:

\section{Tool I: Gugging Swallowing Screen $\underline{\text { (GUSS) }}$}

This tool was developed by Trapl $(2007)^{(27)}$. It was adopted and used to identify alterations of the swallowing process and aspiration risk. It consists of two parts; indirect and direct swallowing test items:

Indirect swallowing test items include vigilance, cough and/or throat clearing, saliva swallow (swallowing successfully, drooling, voice change). The indirect swallowing test items were obtained by asking the patients about each item. Direct swallowing test items include deglutition, cough (involuntary), drooling, voice change. The direct swallowing test items were obtained through observation. The researcher followed the clinical rationale proposed in each item of the GUSS and it was scored using a dichotomous scale of (Yes $=1$ and $\mathrm{No}=0$ ). The total scores of GUSS equal 20; severe dysphagia with high risk for aspiration ranged from (0-9); moderate dysphagia with a risk of aspiration ranged from (10-14); Slight dysphagia with a low risk of aspiration ranged from (15-19) and no dysphagia and minimal risk of aspiration equal (20).
Tool II: Sociodemographic and Clinical Data of Geriatric Patients with \begin{tabular}{lll}
\hline Dysphagia & Structured & Interview
\end{tabular} Schedule

This tool was developed by the researcher based on review of relevant literature to assess the socio demographic characteristics and clinical data of the study subjects. It included two parts:

Part I: socio demographic data such as age, sex, level of education, marital status, occupation before retirement, monthly income, current work status and living style.

Part II: clinical data such as date and reason of hospital admission, medical diagnosis, treatment regimen, side effects of medications, presence of other comorbidities, past medical history, previous hospitalization.

History of dysphagia: its occurrence before and after hospital admission, duration, causes, measures used by the patient to deal with it, consequences of dysphagia, its prevention and treatment.

Tool III: Factors Associated with Aspiration Risk among Geriatric Patients with Dysphagia Structured Interview Schedule

This tool was developed by the researcher based on review of relevant literature to identify factors associated with aspiration risk. It included questions about; history of previous episodes of aspiration such as number of aspiration, type of foods or fluids that lead to aspiration and patient management and reaction. Patient oral condition as presence of normal teeth or dentures upper, lower or both and their condition e.g. loose, well-fitting, complain of toothache and its associated factors and oral hygiene, eating pattern as position during meal, wearing dentures, chewing food properly before swallowing and distracted while eating such as talking and watching T.V. Feeling tired or fatigued while eating or drinking ${ }^{(4,22)}$. Each answer was scored by using a dichotomous scale of (Yes $=1$ and No-0). 


\section{Tool IV: Barthel Index}

This tool was developed by Barthel $(1965)^{(28)}$. It is used to measure performance of activities of daily living (ADL). The tool was translated into Arabic and tested for reliability by Hallaj (2007) $(r=0.971)^{(29)}$. The scale consists of 10 items namely; feeding, bathing, grooming, dressing, controlling bowel, controlling bladder, getting on and off toilet, moving from chair to bed and return, walking on level surface, ascending and descending stairs. A score of zero is given when the geriatric patient cannot meet criteria as defined dependent; one is given when patient needs helps and two when the patient is independent in performing the activity. The total score of the scale is 20 and is classified as follows; 0-7dependent, 8-12need assistance and13-20 independent.

\section{Method}

- An Official letter was issued from the Faculty of Nursing, Alexandria University and forwarded to the Director of the Alexandria Main University Hospital to obtain his approval to carry out the study in the selected medical units in the hospital.

- Approval of the Hospital Director was forwarded to the Head directors of each selected medical units to obtain his approval to carry out the study after being informed about the purpose of the study, the date and time of data collection.

- Survey of all hospital statistical records of the medical units affiliated to the Alexandria Main University Hospital 2016 was carried out by the researcher in order to identify those units with high rate of admission of geriatric patients; these were included in the study. This also helped to estimate the average number of subjects to be included in the study.

- Tool II: Socio demographic and Clinical data of geriatric patients with dysphagia structured interview schedule and tool III: Factors associated with aspiration risk among geriatric patients with dysphagia structured interview schedule were developed by the researcher based on review of relevant literature.

- Tool I and III (Gugging Swallowing Screen and Factors associated with aspiration risk among geriatric patients with dysphagia structured interview schedule) were translated into Arabic language by the researchers and tested for content validity by 7 experts in the related field of the study namely Gerontological Nursing, Medical Surgical Nursing and Critical Care Nursing and the required modifications were carried out accordingly. They were tested for reliability by using Cronbach's coefficient alpha test, the reliability values $=0.771$ and 0.774 respectively.

- A pilot study was carried out on 10 geriatric patients with dysphagia admitted to the geriatric medicine unit of the Alexandria Main University Hospital. The pilot study helped to assess the applicability, clarity and feasibility of the study tools, and to estimate the approximate time needed for data collection. These were not included in the study subjects. The necessary modifications were made accordingly.

- Informed written consent was obtained from patients after explanation of the study purpose.

- The researcher visited all the selected medical units daily in order to assess and identify the geriatric patients fulfilling the inclusion criteria using tool I. This tool includes two parts: the indirect swallowing test and the direct swallowing test.

- Application of the indirect swallowing test:

- The researcher washed her hands, prepared the needed equipment as pillows and explained the Procedure to the geriatric patient. 
- The researcher asks the geriatric patient to sit in high Fowler position with the back straight 90 degree in the bed and his head and neck supported with pillows. The researcher stands at the side of the bed facing the patient. The geriatric patient was assessed for the following vigilance, voluntary cough and saliva swallows.

- A- Vigilance: is used to assess the patient alertness. The patient was asked about his/her name, age, date of hospital admission and the reason of admission to the hospital.The patient is scored one if he/she is alert for at least 15 minutes and a zero score if the patient is not alert (confused).

\section{- B- Voluntary cough:}

The researcher asks the patient to cough voluntary twice successively as strong as he/she can. The patient who is able to cough voluntary as ordered will take a score of one and if he fails the score is zero.

\section{- C- Saliva swallows:}

The researcher tested the patient swallowing reflex by putting her finger under the patient chin in the curve between the chin and the neck above and below the thyroid cartilage and asks the patient to swallow his/her saliva. If the swallowing was successful (e.g. complete elevation of the thyroid cartilage above finger top. The patient is scored one, if it is not successful the patient scores zero.If drooling of saliva occurs during the swallowing test the patient is scored zero, if drooling does not occur the patient score is one.

The researcher asks the patient to say" oh" and listen to the tone of voice. If any change is noted as hoarseness, gurgly, weak, chock on own saliva, patient is scored zero. In case of no changes the patient is scored one.

If the total score of the indirect swallowing test is less than five; the patient is classified as having severe dysphagia with a high risk of aspiration. This was reported by the researcher to the responsible staff of the unit in order to take appropriate action. In this case, stop the test and do not proceed with the direct swallowing test. If the total score of the indirect swallowing test is five this allows the researcher to precede with the direct swallowing test.

\section{- Direct Swallowing Test:}

Before being engaged in the direct swallowing test the following equipment are needed: disposable teaspoon, container with semi-solid food such as custard or yogurt, tissue paper, syringe, disposable cup with water and bread.The direct swallowing test is performed using first semisolid food followed by liquid then solid food.

\section{Semisolid test:}

- The researcher gives the patient from $1 / 3$ to $1 / 2$ teaspoon of custard or yogurt according to the patient preference and asks the patient to swallow. During this process the researcher observes the patient for involuntary cough, drooling and voice changes. If no changes occur the amount of semi-solid food is increased to 3,4 and to 5 teaspoons. The patient is observed immediately and scored according to the following: 


\section{- A- For deglutition:}

If the swallowing was not possible the patient is scored zero. If it was delayed for more than 2 seconds the score is one and if it was successful the score is two.

\section{- B- For involuntary cough:}

The researcher observes the patient for involuntary cough before, during and after swallowing for three consecutive minutes. In case of the occurrence of involuntary cough the patient score is zero and in the absence of involuntary cough the score is one.

\section{- C- For drooling:}

The researcher observes the patient for drooling of saliva during eating.If drooling of saliva occurs the patient is scored zero and if it does not occur the score is one.

\section{- D- For voice change:}

The researcher asks the patient to say "Oh" before and after swallowing.If the patient's voice changes the score is zero and one if it does not change.If the total score obtained in the semisolid test is less than five this is an indication for not proceeding with the liquid test. However if the patient score is five this allows to start the liquid test.

\section{Liquid test:}

- The researcher gives $3 \mathrm{ml}$ of water to the patient and asks him/her to swallow. The researcher observes the patient for any changes such as involuntary cough, drooling and voice changes. In case of no changes the researcher increases gradually the amount of water to $5 \mathrm{ml}$, then to $10 \mathrm{ml}$, to $20 \mathrm{ml}$ and to $50 \mathrm{ml}$. If any changes occur during the procedure the researcher stops the test immediately. For accuracy, the amount of water was measured by the researcher using a sterile disposable syringe.

- The researcher observes and scores the patient according to his condition. The same scoring system used previously in the semisolid test as regards of deglutition, involuntary cough, drooling and voice change was used with the liquid test.

- If the total score obtained by the patient in the liquid test is less than five, this means stop and do not proceed with the solid test. A total score of five is an indication to proceed with the solid test.

\section{Solid test:}

- The researcher asks the patient to chew and swallow a piece of bread then the researcher assesses the patient during swallowing.

- The same scoring system adopted in the semisolid and liquid tests in case of deglutition, involuntary cough, drooling and voice change was used.

- The only difference between deglutition in the solid test is that the period of delay in swallowing is extended to more than 10 seconds while in the other two tests it is 2 seconds. The scoring system is the same in the three tests.

- By the end of the solid test the researcher sum up the total scores obtained by the patient in the indirect and direct swallowing tests together to determine the severity of dysphagia and aspiration risk.

- The researcher used to visit the selected medical units all days of the week except Friday, either in the morning or afternoon. It took from 30-40 minutes to 
collect the necessary data from each of the study subjects after explaining the purpose of the study in order to gain their cooperation.

- The data collection started from the mid October 2017 till the mid-January 2018.

\section{Ethical considerations:}

An informed written consent was obtained from each geriatric patient included in the study after appropriate explanation of the study purpose. Privacy and anonymity of the study subjects and confidentiality of the collected data was assured. The patient was also informed about his right to withdraw from the study without penalty.

\section{Limitation:}

Although assessment of gag reflex is an important part of the study in order to identify factors associated with aspiration risk yet it was refused by almost all the geriatric patients due to the difficulty of test.

\section{Statistical Analysis}

After data collection, data was coded and transformed into specially designed forms as to be suitable for computer feeding and all entered data were verified for any error. Software version 20.0 was used for the analysis of "SPSS" statistical package of social science of the data, Descriptive statistics were done using numbers, percentages, arithmetic mean and standard deviation. Cronbach's alpha method is used to test the reliability. Analytical analysis were done using significance test Chi square test. If more than $20 \%$ of the cells have expected values $<5$ and the level of significance was set as $\leq 0.05$.

\section{Results}

The age of the study geriatric patients ranged from 60 years to 86 years with a mean 69.1 \pm 7.1 years. Females constituted $54.0 \%$ of the study subjects, $55.0 \%$ of the sample were married, $41.0 \%$ illiterate, and $74.0 \%$ are living with their family or relative while $26.0 \%$ are living alone (Table 2).

Table (1) shows the main reasons reported by the study geriatric patients for their present hospital admission. Anorexia was the main reason in $75.0 \%$, general weakness $68.0 \%$, dysphagia $50.0 \%$, sever tachycardia $41.0 \%$ and disturbed level of consciousness $19.0 \%$. While the actual medical diagnosis, obtained from the geriatric patients record was cardiovascular diseases $80.0 \%$ (mainly Hypertension $62.0 \%$, congestive heart failure $14.0 \% \%$, Rapid Atrial Fibrillation 2.0\%, Myocardial Infarction $1.0 \%$ and Deep Vein Thrombosis $1.0 \%)$ followed by hematological diseases $66.0 \%$ (such as Leukemia $34.0 \%$ and Anemia $32.0 \%$ ) liver, gallbladder and pancreatic diseases $64.0 \%$ (as Diabetes mellitus $42.0 \%$ and Liver cirrhosis $22.0 \%$ ) Respiratory diseases reported by $42.0 \%$ as (Pneumonia 33.0\% and Chronic Obstructive Pulmonary Disease 9.0\%).

According to the current prescribed medications, the table shows that, $82.0 \%$ of the study geriatric patients consume analgesics, followed by $79.0 \%$ antibiotics, $77.0 \%$ anti-hypertensive, $74.0 \%$ for each corticosteroids and potassium, $69.0 \%$ diuretics, $64.0 \%$ iron, $55.0 \%$ hypoglycemic agent, $48.0 \%$ anti-inflammatory and $34.0 \%$ chemotherapy.

In relation to the occurrence of side effects from the consumed drugs the same table shows that, dysphagia was the most common side effect reported $64.0 \%$, followed by weak tongue movement $62.0 \%$, dryness of the mouth $56.0 \%$, fatigue $56.0 \%$ and excessive salivation $7.0 \%$.

Among the main reasons for the occurrence of dysphagia as reported by the study geriatric patients are poor mouth condition $74.0 \%$, anorexia $72.0 \%$, sore throat $71.0 \%$ and side effects medication $64.0 \%$. Other reported causes include upper GIT endoscopy $19.0 \%$, Chemotherapy $15.0 \%$, unknown cause $15.0 \%$ and presence of old cerebrovascular Stroke $6.0 \%$. The duration of dysphagia before hospital admission ranges from 2 to 20 days with a 
mean 5.70 \pm 3.16 days. While after hospitalization the range is from 2 to 7 days with a mean $4.54 \pm 1.36$.

Table (2) it appears from the table that $45.5 \%$ of those aged 60 to less than 65 years have slight dysphagia with a low risk of aspiration, while $42.1 \%$ of those aged 65 to less than 75 years have severe dysphagia with a high risk of aspiration. The difference are not statistically significant $\mathrm{p}=0.826$.

Regarding to gender, it is noticed from the table that $38.9 \%$ of females compared to $34.8 \%$ of the males have severe dysphagia with a high risk of aspiration. Moreover $37.0 \%$ of male geriatric patients have slight dysphagia and low risk of aspiration compared to $35.2 \%$ of the females.

The table shows that the higher the level of education the less the dysphagia with a low risk of aspiration $(50 \%$ among university graduates compared to $34.1 \%$ among illiterate). As regards severe dysphagia the table shows that the higher the level of education the lower the severe dysphagia with a high risk of aspiration $(27.3 \%$ among university graduates compared to $31.8 \%$ among illiterate).

No significant relation was observed between the total score of the severity of dysphagia and aspiration risk and age of the study geriatric patients $\mathrm{p}=0.826$, gender $\mathrm{p}=0.912$ and level of education ${ }^{\mathrm{MC}} \mathrm{p}=0.131$. While a statistically significant relation was found only between living arrangement and the severity of dysphagia and risk of aspiration $\mathrm{p}=0.026$.

Table (3) it is noticed that a statistically significant relation was observed between the level of dependency and the severity of dysphagia and risk of aspiration $\mathrm{p}=<0.001$. It is observed from the same table that the study geriatric patients who reported previous history of aspiration are suffering from severe dysphagia with a high risk of aspiration, while those who have history of gastroesophogeal reflux and history of sleep apnea have slight dysphagia with a low risk of dysphagia $(38.4 \%, 47.8 \%$ and $40.9 \%$ respectively). The differences are not statistically significant, $\mathrm{P}=0.763, \mathrm{P}=0.329$ and $\mathrm{P}=0.826$ respectively.

The table also shows that $42.9 \%$ of geriatric patients who have received chemotherapy have severe dysphagia with a high risk of aspiration, $32.1 \%$ have moderate dysphagia with a risk of aspiration and $25.0 \%$ have slight dysphagia with a low risk of aspiration. A statistically significant relation was observed among patients who received chemotherapy and aspiration risk $\mathrm{P}=0.035$. On the other side, no significant effect was noted between geriatric patients who have received radiation therapy on neck and the severity of dysphagia and aspiration risk $\mathrm{P}=0.089$.

Table (4) reveals the relation between the current medical diagnosis and side effects of current medications used by the study geriatric patients and the severity of dysphagia and aspiration risk. No statistically significant relation between patient diagnosis and the severity of dysphagia and aspiration risk.

As regard side effects of current medications used by the study geriatric patients and the severity of dysphagia and aspiration risk, a statistically significant relation was observed between the occurrence of weak tongue movement and dryness of the mouth as side effects of medications and the severity of dysphagia and aspiration risk $\mathrm{P}=0.036, \quad \mathrm{P}=0.048$ respectively. While no statistically significant relation was observed between general weakness, excessive salivation and dysphagia as side effects of medications and the severity of dysphagia and aspiration.

Table (5) reveals the relation between causes of aspiration and the severity of dysphagia and aspiration risk. The severity of dysphagia and aspiration risk is affected significantly by the intake of semi-solid foodp $=0.033$. It also appears from the same table that no significant relation between type of fluid or the method used while drinking and the severity of dysphagia and aspiration risk. 
Table (6) shows the relation between risk behaviors of the study geriatric patients leading to aspiration and the severity of dysphagia and aspiration risk. A high statistically significant relations were observed between filling mouth with food, feeling tired and fatigue while eating or drinking and the severity of dysphagia and aspiration risk $\mathrm{P}=0.001$ and $\mathrm{P}=0.001$ respectively. One the other hand no significant relation between either wearing denture while eating or drinking while mouth is full with food or chewing food well or distraction during eating and drinking or having Poor oral hygiene $\mathrm{P}=0.441, \mathrm{P}=0.634, \mathrm{P}=0.238, \mathrm{P}=0.083$, and $\mathrm{P}=0.328$ respectively.

\section{Discussion}

Dysphagia is a common problem among geriatric patients ${ }^{(30)}$. This is because normal aging result in changes in structure, motility, coordination and sensitivity of the swallowing process, which in turn affects the four stages of swallowing ${ }^{(31,32)}$. Moreover elderly persons are more prone to stroke, heart failure and diabetes mellitus, which may increase the risk of dysphagia. In addition to their over use of sedative and psychotropic medications and general frailty $^{(33,34)}$. Dysphagia makes geriatric patients more liable to aspiration, long term hospitalization and higher mortality rate ${ }^{35-}$ 37). Early identification and management of dysphagia aims to prevent aspiration and reestablish safe swallowing ${ }^{(38-40)}$.

So, this study aimed to identify factors associated with aspiration risk among geriatric patients with dysphagia.

The current study revealed that, severity of dysphagia and aspiration risk are prevalent among geriatric patients aged 65 years and older (Table 2). This may be due to decrease level of education and poor eating habits in this age group than other groups. In addition the age related changes that affect all body systems and in particular the swallowing process, decreased peristaltic activity in the esophagus and relaxation of the lower esophageal sphincter these may cause delayed emptying of the esophagus and an increased risk of aspiration $^{(41)}$. These findings are in line with the findings of a study carried out in Alexandrian $(2006)^{(19)}$ which revealed that the prevalence of dysphagia among hospitalized geriatric patients with stroke more than 65 years old was $45 \%$.The same was also reported from a study in Germany $(2016)^{(31)}$ which stated that the prevalence of oropharyngeal dysphagia among hospitalized geriatric patients aged 65 years and more was $47 \%$.

Severe dysphagia with a high risk for aspiration was associated with cardiovascular diseases as (hypertension and congestive heart failure) followed by hematological diseases as (leukemia and anemia), liver, gallbladder and pancreatic diseases as (diabetes mellitus) (tables 1\&4). These medical diagnoses usually cause frailty and weakness of the elderly which may affect the swallowing process. These findings support the findings of the study done in China $(2016)^{(22)}$ which indicated that heart failure, diabetes and general frailty place older adults at risk for dysphagia and aspiration. Other studies in Japan and European $(2015)^{(17,42)}$ revealed that geriatric patients with malignancy and hematological diseases were significantly higher in severity of dysphagia and aspiration risk. Although the dysphagia and aspiration risk is more common among geriatric patients suffering from stroke ${ }^{(43-}$ ${ }^{45)}$, yet the contrary was observed in this study where only $3 \%$ of the geriatric patients with stroke suffered from dysphagia and aspiration risk (table 4). This difference between the result of the present study and other studies might be related to the small number of geriatric patients with stroke encountered among study subjects.

Polypharmacy is common among geriatric patients. This is because of the comorbidities associated with aging and requiring multiple drug use. The most common drugs used by the study subjects were antibiotics, antihypertensive, corticosteroid and analgesics (table 1). 
These medications may cause certain side effect which may affect the swallowing process such as weak tongue movement and dryness of the mouth. These side effects were significantly associated with the severity of dysphagia and aspiration risk (table 4). The same was reported from other studies $^{(17,46)}$.

A statistically significant relation was observed between geriatric patients who were treated with chemotherapy and the severity of dysphagia and aspiration risk (table 3). This may be due to the effect of chemotherapy on the swallowing muscles which may lead to their weakness, reduction in tongue strength and prolonged oral transit times during swallowing and also mouth dryness. Also, the geriatric patients who receive chemotherapy are usually tired and fatigued. Feeling tired and fatigue are among the risk factors for aspiration. On the other hand no significant relation was noted between geriatric patients who received radiation therapy on neck and the severity of dysphagia and aspiration risk (table 3). These study findings are in harmony with those reported in Brazil $(2013)^{(47)}$ which revealed a statistically significant associated between geriatric patients who received chemotherapy and the severity of dysphagia and aspiration risk. While no significant relation was reported between radiation therapy and dysphagia and aspiration risk. Also the present study supports the findings of a study done in Japan (2017) ${ }^{(48)}$ which revealed a relation between chemotherapy and dysphagia and aspiration risk. Contrary to the findings of the present study a significant relation between radiation therapy and dysphagia and aspiration risk was reported in another study ${ }^{(48)}$.

As regards the level of dependency and the severity of dysphagia and aspiration risk among geriatric patients (table 3), it is observed that the severity of dysphagia and aspiration risk increases with the increase in the level of dependency. This may be due to age-related decline in muscle strength and degeneration of nerve conduction velocity which affect the swallowing process ${ }^{(49-51)}$. These results support the findings of two other studies in USA 2013 and $2017^{(52,53)}$. On the other hand a study in Korea $2016^{(54)}$ revealed that geriatric patients needing partial assistance in their daily living experience higher risk for dysphagia and aspiration risk. However, all studies and the present one agree that independence is important for effective swallowing.

The current study revealed that the severity of dysphagia and aspiration risk is affected significantly by the intake of semisolid food (table5). This result supports another study carried out in Alexandria $(2006)^{(19)}$ which revealed that, more than half of the studied patients had pocketing with pure potatoes and have severe dysphagia with a high risk of aspiration. This may be related to abnormal tongue function and poor control of cheeks muscles. Contrary studies in USA $(2007 \& 2008)^{(27,55)}$ and Germany $(2014)^{(43)}$ reported that patients with dysphagia swallow better semisolid texture than liquid and solid.

The method used by geriatric patients in drinking whether by syringe or straw affected the degree of dysphagia and aspiration risk. Where those patients were suffer from severe dysphagia with a high risk of aspiration (table 5). It may be due to the spilling of bolus of fluids rapidly in the posterior pharynx and this causes aspiration. This result supports a study in USA $(2013)^{(56)}$ which revealed that the risk of penetration and aspiration is significantly higher for syringe and straw versus cup drinking.

Poor eating habit such as excess food in the mouth, feeling tired and fatigue while eating and drinking are significant risk behaviors associated with the severity of dysphagia and aspiration risk (table 6). This may be explained by the fact that risk behaviors as poor eating habit and fatigue usually create problems with swallowing particularly among old people and may lead to aspiration risk. The same was reported 
from a study in Germany (2014) $)^{(57)}$ and Northeast of Italy $(2017)^{(58)}$.

Among the others risk behaviors associated with dysphagia and aspiration risk among geriatric patients is improper use of dentures. Although the majority of the study geriatric patients use dentures, yet less than half do not wear them while eating. These were considered to have severe dysphagia with a high risk of aspiration (table 6). This is because dentures decrease the secretion of saliva, causing formation of food bolus obstructions ${ }^{(59)}$. Also a study done in Korea $(2016)^{(54)}$ revealed that geriatric patients who use dentures, had significant high-risk for dysphagia and aspiration. Also, the present study showed that, poor oral health condition of the geriatric patients is associated with severe dysphagia with a high risk of aspiration (table 6). It may be due to the fact that neglection of oral health condition with advancing age leads to mouth dryness and sores and cause dysphagia and aspiration risk ${ }^{(60)}$. This finding is in line with a study carried out in Taiwan $(2017)^{(61)}$. Another study in USA (2017) revealed that, poor oral hygiene results in change in the composition of oropharyngeal flora and is associated with a greater colonization by more virulent organisms which make geriatric patients more risky for aspiration.

In the current study, the geriatric patients who reported previous history of aspiration suffered from severe dysphagia with a high risk of aspiration (table 3). This may be due to impairment in the gag reflex, decreased peristaltic activity in the esophagus and relaxation of the lower esophageal sphincter. This usually results in delayed emptying of the esophagus and an increased risk of aspiration. Moreover the patient who suffered from previous aspiration may consider it as a normal phenomenon with aging and do not seek treatment which put them at risk for further aspiration. This result supports a study carried out in USA $(2015)^{(62)}$.
Regarding sex, the present study illustrates that the severity of dysphagia and aspiration risk is observed more in females than males (table 2).There is no biological explanation for this gender difference, but it may be because of the greater likelihood of women to report trouble in swallowing than men. This finding is in line with the findings of a study carried out in USA $(2007)^{(63)}$. While a study in Spain $(2010)^{(64)}$ reported no gender difference emphasizing that this is not a risk factor for dysphagia. Contrary to the result of the present study a study done in Korea $(2013)^{(65)}$ reported that dysphagia is associated more with males than females.

Education is considered the cornerstone for preventing dysphagia and aspiration risk. The current study revealed that the severity of dysphagia and aspiration risk was encountered more among illiterate geriatric patients (table 2). Decrease level of education among geriatric patients makes them more risky for dysphagia and aspiration risk not only because they lack knowledge about dysphagia but also their belief that it is a natural process of aging. The same findings were reported from a study in Korea $(2016)^{(54)}$.

As regard the living condition, although the majority of the study subjects who live with their families, showed sever dysphagia with a high risk of aspiration compared to the minority who live alone (table 2). This may be due to family members have responsibilities of their own as work and care of other children and also may be related decrease awareness of family member about dysphagia and aspiration risk. Moreover, it may be also due to the awareness of those who live alone that they have to depend on themselves thus they take certain measures to ensure swallowing safely ${ }^{(66)}$.

\section{Conclusion}

Based on the results of the current study, it can be concluded that the severity of dysphagia and aspiration risk were affected by several factors as the geriatric 
patients living arrangement, level of dependency, weak tongue movement and dryness of the mouth as a side effect of medications, and treatment with chemotherapy. Also some risk behaviors assumed by geriatric patients lead to dysphagia and aspiration risk. These include mouth full with foods while eating, feeling tired and fatigued during meals. Moreover dysphagia and aspiration risk among hospitalized geriatric patients were associated with illiteracy and specific medical diagnosis as (hypertension, congestive heart failure, leukemia, anemia and diabetes mellitus) and some medications as (antibiotics, corticosteroids and analgesics.

\section{Recommendations}

Based on the findings of this study, the following recommendations are suggested:

- Comprehensive assessment of geriatric patients for dysphagia and aspiration risk should be a routine and basic procedure of the gerontological nurse in the hospital in order to identify early those who are at risk and implement appropriate nursing interventions to prevent complications.

- Develop continuing training program for staff nurses in all medical departments in the hospital about how to assess the geriatric patients for dysphagia and aspiration risk and how to manage it by postural adjustment, diet modification.

- Gerontological nurse should collaborate and communicate with members of the health care team as medical staff for early management and rehabilitation of the geriatric patients with dysphagia.
- Family members should be involved in the planning of care for their geriatric patients with dysphagia and aspiration risk through education about how to prepare modified diet and precautions to be followed in feeding them safely.

- Teach older adults about the importance of following proper eating habits such as wearing dentures, chewing food properly; avoid talking while eating and drinking while mouth full with food.

- Develop a new nursing specialty in Egypt namely Dysphagia Nurse Specialist who is qualified and skillful in managing geriatric patients with dysphagia and aspiration risk. 
Table (1): Distribution of the study geriatric patients with dysphagia according to their present hospital admission, medical diagnosis, medications, occurrence of side effects and history of dysphagia

\begin{tabular}{|c|c|c|}
\hline Items & $\begin{array}{c}\text { Number } \\
(\mathrm{N}=100)\end{array}$ & $\begin{array}{c}\text { Percent } \\
\%\end{array}$ \\
\hline $\begin{array}{l}\text { Reasons for the current hospital admission\# } \\
\text { Anorexia } \\
\text { General weakness } \\
\text { Dysphagia } \\
\text { Sever tachycardia } \\
\text { Disturbed level of consciousness } \\
\end{array}$ & $\begin{array}{l}75 \\
65 \\
50 \\
41 \\
19 \\
\end{array}$ & $\begin{array}{l}75.0 \\
68.0 \\
50.0 \\
41.0 \\
19.0\end{array}$ \\
\hline $\begin{array}{l}\text { Current medical diagnosis\# } \\
\text { Cardiovascular diseases } \\
\text { Hematology diseases } \\
\text { liver, gallbladder and pancreatic diseases } \\
\text { Respiratory diseases } \\
\text { Urological diseases } \\
\text { Gastrointestinal diseases } \\
\text { Rheumatology and immunology diseases } \\
\text { Others }\end{array}$ & $\begin{array}{c}80 \\
66 \\
64 \\
42 \\
29 \\
25 \\
9 \\
6 \\
\end{array}$ & $\begin{array}{c}80.0 \\
66.0 \\
64.0 \\
42.0 \\
29.0 \\
25.0 \\
9.0 \\
6.0 \\
\end{array}$ \\
\hline $\begin{array}{l}\text { Current Prescribed medications\# } \\
\text { Analgesics } \\
\text { Antibiotics } \\
\text { Anti-hypertensive } \\
\text { Corticosteroids } \\
\text { Potassium } \\
\text { Diuretics } \\
\text { Iron } \\
\text { Hypoglycemic agent } \\
\text { Anti-inflammatory } \\
\text { Chemotherapy } \\
\end{array}$ & $\begin{array}{l}82 \\
79 \\
77 \\
74 \\
74 \\
69 \\
64 \\
55 \\
48 \\
34\end{array}$ & $\begin{array}{l}82.0 \\
79.0 \\
77.0 \\
74.0 \\
74.0 \\
69.0 \\
64.0 \\
55.0 \\
48.0 \\
34.0\end{array}$ \\
\hline $\begin{array}{l}\text { Side effects of medications\# } \\
\text { Dysphagia } \\
\text { Weak tongue movement } \\
\text { Dry Mouth } \\
\text { Fatigue } \\
\text { Excessive salivation }\end{array}$ & $\begin{array}{c}64 \\
62 \\
56 \\
56 \\
7 \\
\end{array}$ & $\begin{array}{c}64.0 \\
62.0 \\
56.0 \\
56.0 \\
7.0 \\
\end{array}$ \\
\hline $\begin{array}{l}\text { Causes of dysphagia either before or after hospitalization\# } \\
\text { Poor mouth condition } \\
\text { Anorexia } \\
\text { Sore throat } \\
\text { Side effect of medication } \\
\text { After upper GIT endoscopy } \\
\text { Chemotherapy } \\
\text { Unknown } \\
\text { Presence of old Cerebrovascular Stroke } \\
\end{array}$ & $\begin{array}{c}(\mathbf{N}=\mathbf{1 0 0}) \\
74 \\
72 \\
71 \\
64 \\
19 \\
15 \\
15 \\
6 \\
\end{array}$ & $\begin{array}{c}74.0 \\
72.0 \\
71.0 \\
64.0 \\
19.0 \\
15.0 \\
15.0 \\
6.0 \\
\end{array}$ \\
\hline $\begin{array}{l}\text { Duration of dysphagia before hospitalization (in days) } \\
\text { Less than } 5 \text { days } \\
5- \\
10+ \\
\end{array}$ & $\begin{array}{c}\mathbf{( N = 5 0 )} \\
26 \\
3 \\
21\end{array}$ & $\begin{array}{c}52.0 \\
6.0 \\
42.0\end{array}$ \\
\hline Mean \pm SD. & \multicolumn{2}{|c|}{$5.70 \pm 3.16$} \\
\hline $\begin{array}{l}\text { Duration of dysphagia after hospitalization (in days) } \\
\text { Less than } 5 \text { days } \\
5- \\
10+ \\
\end{array}$ & $\begin{array}{c}\mathbf{N}=\mathbf{9 7}) \\
57 \\
15 \\
25 \\
\end{array}$ & $\begin{array}{l}58.7 \\
15.4 \\
25.7\end{array}$ \\
\hline Mean \pm SD & \multicolumn{2}{|c|}{$4.54 \pm 1.36$} \\
\hline
\end{tabular}


Aspiration Risk and Dysphagia

Table (2): Relation between socio-demographic characteristics of the study geriatric patients and the severity of dysphagia and aspiration risk

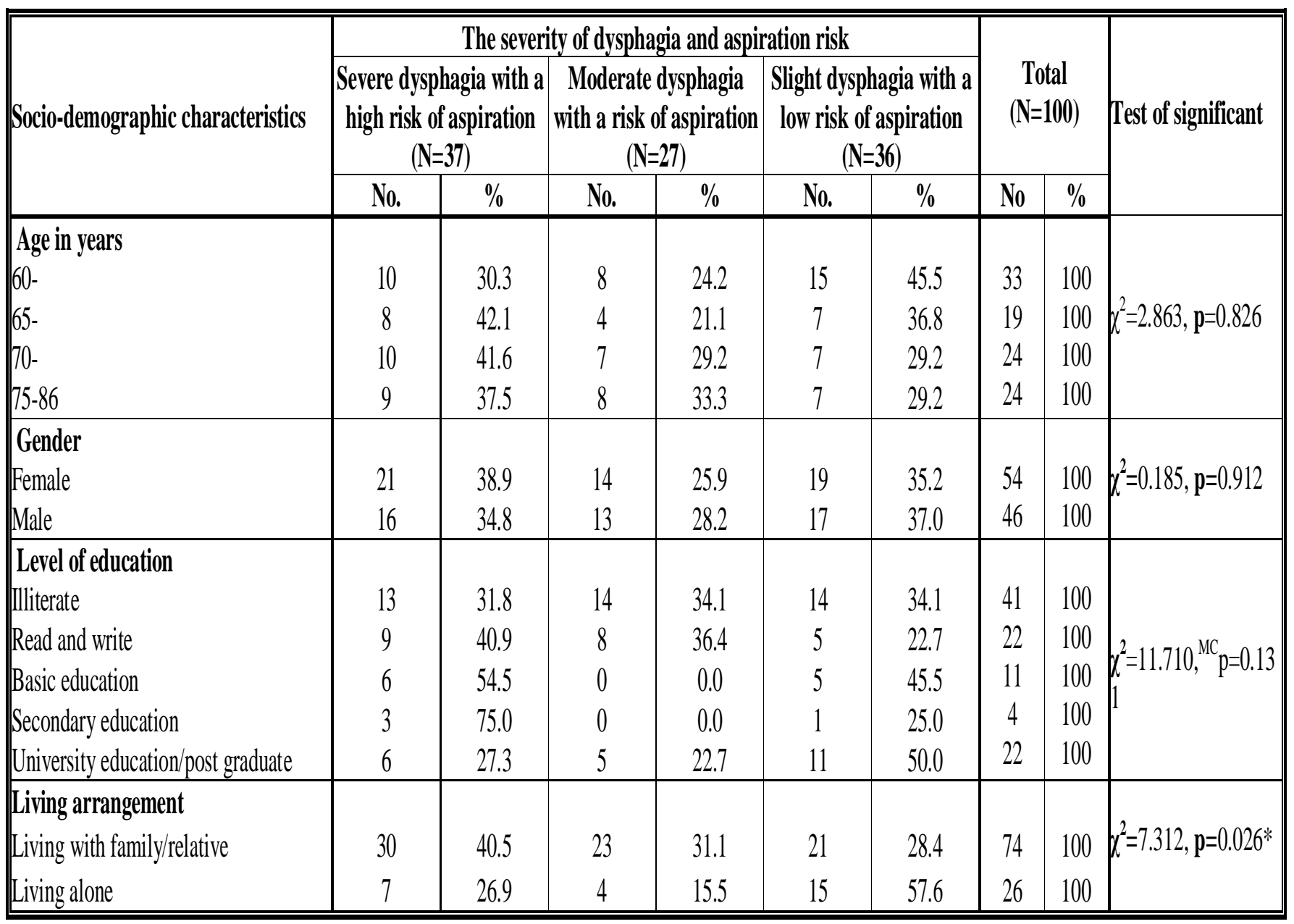

ұ2: Chi square test

MC: Monte Carlo

*Statistically significant at $p \leq 0.05$ 
Aspiration Risk and Dysphagia

Table (3): Relation between the study geriatric patients' level of dependency, history of aspiration risk, and chemo or radio-therapy and the severity of dysphagia and aspiration risk

\begin{tabular}{|c|c|c|c|c|c|c|c|c|c|}
\hline \multirow{3}{*}{ Items } & \multicolumn{6}{|c|}{\begin{tabular}{|c|} 
The severity of dysphagia and aspiration risk \\
\end{tabular}} & \multirow{2}{*}{\multicolumn{2}{|c|}{$\begin{array}{c}\text { Total } \\
(\mathrm{N}=100)\end{array}$}} & \multirow{3}{*}{ Test of significant } \\
\hline & \multicolumn{2}{|c|}{\begin{tabular}{|c|} 
Severe dysphagia with a \\
high risk of aspiration \\
$(\mathrm{N}=37)$
\end{tabular}} & \multicolumn{2}{|c|}{$\begin{array}{c}\text { Moderate dysphagia } \\
\text { with a risk of aspiration } \\
(\mathrm{N}=27)\end{array}$} & \multicolumn{2}{|c|}{$\begin{array}{c}\text { Slight dysphagia with a } \\
\text { low risk of aspiration } \\
(\mathrm{N}=36)\end{array}$} & & & \\
\hline & No. & $\%$ & $\mathrm{~N}_{0}$. & $\%$ & No. & $\%$ & No & $\%$ & \\
\hline Level of dependency & & & & & & & & & \\
\hline Independent ( 13-20) & 4 & 16.7 & 2 & 8.3 & 18 & 75.0 & 24 & 100 & $\chi^{2}=23.745$ \\
\hline Need assistant (8-12) & 22 & 38.6 & 21 & 36.8 & 14 & 24.6 & 57 & 100 & $\mathrm{p}=<0.001^{*}$ \\
\hline Dependent (0-7) & 11 & 57.8 & 4 & 21.1 & 4 & 21.1 & 19 & 100 & \\
\hline History of aspiration risk & & & & & & & & & \\
\hline Previous aspiration & 33 & 38.4 & 23 & 26.7 & 30 & 34.9 & 86 & 100 & $\chi^{2}=0.540, P=0.763$ \\
\hline Gastro-esophageal reflux & 8 & 34.8 & 4 & 17.4 & 11 & 47.8 & 23 & 100 & $\chi^{2}=2.222, \mathrm{P}=0.329$ \\
\hline Sleep apnea & 8 & 36.4 & 5 & 22.7 & 9 & 40.9 & 22 & 100 & $\chi^{2}=0.383, P=0.826$ \\
\hline Received chemotherapy & & & & & & & & & \\
\hline Yes & 24 & 42.9 & 18 & 32.1 & 14 & 25.0 & 56 & 100 & $\chi=6.105$ \\
\hline No & 13 & 29.5 & 9 & 20.5 & 22 & 50.0 & 44 & 100 & \\
\hline Received radiation therap & & & & & & & & & \\
\hline neck & & & & & & & & & $\chi^{2}=4.835$ \\
\hline Yes & 12 & 54.5 & 6 & 27.3 & 4 & 18.2 & 22 & 100 & $\mathrm{P}=0.089$ \\
\hline No & 25 & 32.1 & 21 & 26.9 & 32 & 41.0 & 78 & 100 & \\
\hline
\end{tabular}

ұ2: Chi square test

*Statistically significant at $p \leq 0.05$

${ }^{*} *$ statistically significant at $p \leq 0.001$ 
Aspiration Risk and Dysphagia

Table (4): Relation between the study geriatric patients' present medical diagnosis and side effects of consumed medications and the severity of dysphagia and aspiration risk

\begin{tabular}{|c|c|c|c|c|c|c|c|c|c|}
\hline \multirow{3}{*}{ Items } & \multicolumn{6}{|c|}{\begin{tabular}{|c|} 
The severity of dysphagia and aspiration risk \\
\end{tabular}} & \multirow{2}{*}{\multicolumn{2}{|c|}{$\begin{array}{c}\text { Total } \\
(\mathrm{N}=100)\end{array}$}} & \multirow{3}{*}{ Test of significant } \\
\hline & \multicolumn{2}{|c|}{\begin{tabular}{|c|}
$\begin{array}{c}\text { Severe dysphagia with } \\
\text { a high risk of aspiration } \\
(\mathrm{N}=37)\end{array}$ \\
\end{tabular}} & \multicolumn{4}{|c|}{\begin{tabular}{|c|c|} 
Moderate dysphagia & Slight dysphagia with a \\
with a risk of aspiration & low risk of aspiration \\
$(\mathrm{N}=27)$ & $(\mathrm{N}=36)$ \\
\end{tabular}} & & & \\
\hline & No. & $\%$ & No. & $\%$ & No. & $\%$ & $\mathrm{~N}_{0}$ & $\%$ & \\
\hline \multicolumn{10}{|l|}{ Medical diagnosis } \\
\hline Cardiovascular diseases & 30 & 37.5 & 23 & 28.8 & 27 & 33.7 & 80 & 100 & $\chi^{2}=1.043, \mathrm{P}=0.594$ \\
\hline Hematology diseases & 26 & 39.4 & 17 & 25.8 & 23 & 34.8 & 66 & 100 & $\chi^{2}=0.483, P=0.785$ \\
\hline liver, gallbladder and pancreatic diseases & 24 & 37.5 & 18 & 28.1 & 22 & 34.4 & 64 & 100 & $\chi^{2}=0.226, P=0.893$ \\
\hline Respiratory system diseases & 16 & 38.1 & 12 & 28.6 & 14 & 33.3 & 42 & 100 & $\chi^{2}=0.233, \mathrm{P}=0.890$ \\
\hline Urinary system diseases & 7 & 24.1 & 8 & 27.6 & 14 & 48.3 & 29 & 100 & $\chi^{2}=3.541, P-0.170$ \\
\hline Gastrointestinal system diseases & 10 & 40.0 & 6 & 24.0 & 9 & 36.0 & 25 & 100 & $\chi^{2}=0.192, P=0.908$ \\
\hline Rheumatology and immunology diseases & 3 & 33.3 & 1 & 11.1 & 5 & 55.6 & 9 & 100 & $\chi^{2}=1.804,{ }^{\mathrm{MC}} \mathrm{p}=0.334$ \\
\hline The motor system diseases & 0 & 0.0 & 1 & 33.3 & 2 & 66.7 & 3 & 100 & $\chi^{2}=2.017,{ }^{\mathrm{MC}} \mathrm{p}=0.369$ \\
\hline Neurological diseases & 3 & 100.0 & 0 & 0.0 & 0 & 0.0 & 3 & 100 & $\chi^{2}=3.584,{ }^{\mathrm{MC}} \mathrm{p}=0.108$ \\
\hline \multicolumn{10}{|l|}{ Side effects of medications } \\
\hline Dysphagia & 25 & 39.1 & 17 & 26.6 & 22 & 34.3 & 64 & 100 & $\chi^{2}=0.347, P=0.841$ \\
\hline Weak tongue movement & 22 & 35.5 & 22 & 35.5 & 18 & 29.0 & 62 & 100 & $\chi^{2}=6.651, P=0.036^{*}$ \\
\hline Mouth dryness & 26 & 46.4 & 15 & 26.8 & 15 & 26.8 & 56 & 100 & $\chi^{2}=6.062, \mathrm{P}=0.048^{*}$ \\
\hline General weakness & 25 & 44.7 & 13 & 23.2 & 18 & 32.1 & 56 & 100 & $\chi^{2}=3.211, P=0.201$ \\
\hline Excessive salivation & 1 & 14.3 & 1 & 14.3 & 5 & 71.4 & 7 & 100 & $\chi^{2}=3.402, \quad p=0.148$ \\
\hline
\end{tabular}

ұ2: Chi square test

MC: Monte Carlo

*Statistically significant at $p \leq 0.05$ 
Aspiration Risk and Dysphagia

Table (5): Relation between causes of aspiration among the study geriatric patients and the severity of dysphagia and aspiration risk

\begin{tabular}{|c|c|c|c|c|c|c|c|c|c|}
\hline \multirow{3}{*}{ Causes of aspiration } & \multicolumn{6}{|c|}{ The severity of dysphagia and aspiration risk } & & & \multirow{3}{*}{ Test of significant } \\
\hline & \multicolumn{2}{|c|}{$\begin{array}{l}\text { Severe dysphagia with a } \\
\text { high risk of aspiration } \\
\qquad(\mathrm{N}=37)\end{array}$} & \multicolumn{2}{|c|}{$\begin{array}{l}\text { Moderate dysphagia with a } \\
\text { risk of aspiration } \\
(\mathrm{N}=27)\end{array}$} & \multicolumn{2}{|c|}{$\begin{array}{l}\text { Slight dysphagia with } \\
\text { a low risk of aspiration } \\
\qquad(\mathrm{N}=36)\end{array}$} & \multicolumn{2}{|c|}{$\begin{array}{c}\text { Total } \\
(\mathrm{N}=100)\end{array}$} & \\
\hline & No. & $\%$ & No. & $\%$ & No. & $\%$ & No & $\%$ & \\
\hline Type of food & & & & & & & & & \\
\hline Solid food & 20 & 46.5 & 10 & 23.3 & 13 & 30.2 & 43 & 100 & $\chi^{2}=1.610, \quad \mathrm{MC}=0.449$ \\
\hline Citrus food & 17 & 48.6 & 10 & 28.6 & 8 & 22.8 & 35 & 100 & $\chi^{2}=2.594, \quad p=0.286$ \\
\hline Semi solid food & 17 & 65.4 & 5 & 19.2 & 4 & 15.4 & 26 & 100 & $x^{2}=6.820 ; 0.033^{*}$ \\
\hline Any type of foods & 15 & 65.2 & 4 & 17.4 & 4 & 17.4 & 23 & 100 & $x^{2}=4.853,0.088$ \\
\hline Type of fluid & & & & & & & & & \\
\hline Water & 31 & 48.4 & 19 & 29.7 & 14 & 21.9 & 64 & 100 & $\chi^{2}=4.184, \quad p=0.057$ \\
\hline Citrus juice & 22 & 45.8 & 13 & 27.1 & 13 & 27.1 & 48 & 100 & $\chi^{2}=0.812, P=0.666$ \\
\hline Soup & 16 & 55.2 & 5 & 17.2 & 8 & 27.6 & 29 & 100 & $\chi^{2}=3.375, P=0.185$ \\
\hline Method of drinking & & & & & & & & & \\
\hline Straw & 23 & 46.9 & 15 & 30.7 & 11 & 22.4 & 49 & 100 & $\chi^{2}=0.543, \quad \mathrm{MC}=0.876$ \\
\hline Cup & 16 & 44.4 & 10 & 27.8 & 10 & 27.8 & 36 & 100 & $\chi^{2}=0.544, P=0.762$ \\
\hline Spoon & 11 & 52.4 & 4 & 19.0 & 6 & 28.6 & 21 & 100 & $\chi^{2}=1.445, P=0.486$ \\
\hline Syringe & 10 & 58.8 & 3 & 17.6 & 4 & 23.6 & 17 & 100 & $\chi^{2}=1.613,{ }^{\mathrm{MC}} \mathrm{p}=0.478$ \\
\hline
\end{tabular}

$\chi 2$ : Chi square test

MC: Monte Carlo

*Statistically significant at $p \leq 0.05$ 
Aspiration Risk and Dysphagia

Table (6): Relation between risk behaviors leading to aspiration and the severity of dysphagia and aspiration risk among the study geriatric patients

\begin{tabular}{|c|c|c|c|c|c|c|c|c|c|}
\hline \multirow{3}{*}{$\begin{array}{l}\text { Risk behaviors leading to } \\
\text { aspiration }\end{array}$} & \multicolumn{6}{|c|}{ The severity of dysphagia and aspiration risk } & & & \multirow{3}{*}{ Test of significant } \\
\hline & \multicolumn{2}{|c|}{$\begin{array}{c}\text { Severe dysphagia with a } \\
\text { high risk of aspiration } \\
(\mathrm{N}=37)\end{array}$} & \multicolumn{2}{|c|}{$\begin{array}{l}\text { Moderate dysphagia } \\
\text { with a risk of aspiration } \\
\qquad(\mathrm{N}=27)\end{array}$} & \multicolumn{2}{|c|}{$\begin{array}{c}\text { Slight dysphagia with a } \\
\text { low risk of aspiration } \\
(\mathrm{N}=36)\end{array}$} & \multicolumn{2}{|c|}{$\begin{array}{c}\text { Total } \\
(\mathrm{N}=100)\end{array}$} & \\
\hline & No. & $\%$ & No. & $\%$ & No. & $\%$ & No. & $\%$ & \\
\hline Not wearing denture while eating & 22 & 44.9 & 13 & 26.5 & 14 & 28.6 & 49 & 100 & $\chi^{2}=1.636, P=0.441$ \\
\hline $\begin{array}{l}\text { Drinking while mouth is full with } \\
\text { food }\end{array}$ & 30 & 36.2 & 24 & 28.9 & 29 & 34.9 & 83 & 100 & $\chi^{2}=0.913, P=0.634$ \\
\hline Not Chewing food well & 31 & 41.3 & 20 & 26.7 & 24 & 32.0 & 75 & 100 & $\chi^{2}=2.868, P=0.238$ \\
\hline $\begin{array}{l}\text { Distraction during eating and } \\
\text { drinking }\end{array}$ & 32 & 42.7 & 20 & 26.7 & 23 & 30.6 & 75 & 100 & $\chi^{2}=4.986, P=0.083$ \\
\hline Mouth full with food & 32 & 46.4 & 20 & 29.0 & 17 & 24.6 & 69 & 100 & $\chi^{2}=13.596, P=0.001^{*}$ \\
\hline $\begin{array}{l}\text { Feeling of tiredness and fatigue } \\
\text { during eating or drinking }\end{array}$ & 32 & 46.4 & 20 & 29.0 & 17 & 24.6 & 69 & 100 & $\chi^{2}=13.596, P=0.001^{*}$ \\
\hline Poor oral hygiene & 24 & 38.8 & 19 & 30.6 & 19 & 30.6 & 62 & 100 & $x^{2}=2.231, P=0.328$ \\
\hline
\end{tabular}

22: Chi square test

MC: Monte Carlo

$*$ Statistically significant at $p \leq 0.05$ 


\section{References}

1. Wirth R, Dziewas R, Beck A, Clavé P, Juergen $\mathrm{H}$, Leischker A, Martino R, Pluschinski P, Rösle A, Shaker R, Warnecke T, Sieber C, Volkert D. Oropharyngeal Dysphagia in Older Persons. Clinical Intervention Aging Journal 2016; 11: 189-208.

2. Kuroda O. Clinical Characteristics Associated with Dysphagia in Hospitalized Elderly. The Journal of Aging Research and Clinical Practice 2012; 41: 376-81.

3. Balzer KM. Drug-Induced Dysphagia. International Journal of Multiple Sclerosis Care 2000; 2(1): 40-50.

4. Touhy TA. Toward Healthy Aging: Human needs and nursing response. 9th ed. China: Elsevier CO, 2016; 185.

5. Meiner SE. Gerontologic Nursing. 5th ed. USA: Elsevier CO, 2015; 487-88.

6. Chan D, Phoon S, Yeoh E. Dysphagia and Aspiration in Older People. Australian Journal of Aging 2011; 30(2): 98-103.

7. Luke's S. Aspiration from Dysphagia 2017. Available at: https://www.saintlukeshealthsystem.org. Retrieved on 09/3/2017.

8. Eisenstaedt S. Dysphagia and aspiration pneumonia in older adults. Journal of the American Association of Nurse Practitioners 2010; 22(1):17-22.

9. Ramsey DJ, Smithard DG, Kalra L. Early assessments of dysphagia and aspiration risk in acute stroke patients. Stroke 2003; 34:1252-57.

10. Gradon JD. Community-acquired pneumonia in the older patient. Journal of Clinical Gerontology and Geriatrics 2006; 14(1): 39-45.
11. Cichero J, Altman KW. Definition, prevalence and burden of oropharyngeal dysphagia: A serious problem among older adults worldwide and the impact on prognosis and hospital resources. Nestlé Nutrition Institute Workshop 2012; 72: 111.

12. Wakasugi $\mathrm{Y}$, Tohara $\mathrm{H}$, Hattori $\mathrm{F}$, Motohashi Y, Nakane A, Goto S. Screening Test for Silent Aspiration at the Bedside. Dysphagia 2008; 23:364-70.

13. Martino R, Foley N, Bhogal S. Dysphagia after stroke: Incidence, diagnosis and pulmonary complications. Stroke 2005; 36(12): 2756-63.

14. Malagelada J, Bazzoli F, Elewaut A. Dysphagia. World Gastroenterology Organization Practice Guidelines 2007: 114.

15. Leder SB, Suiter DM. An epidemiologic study on aging and dysphagia in the acute care hospitalized population: 2000-2007. Gerontology 2009; 55: 714-18.

16. Serra-Prat M, Hinojosa G, Palomera E, Arreola V, Clavé P. Prevalence of oropharyngeal dysphagia and impaired safety and efficacy of swallowing in independently living older persons. Journal of the American Geriatrics Society 2011; 59: 186-87.

17. Carrión S, Cabré M, Monteis R, Roca M, Palomera E. Oropharyngeal dysphagia is a prevalent risk factor for malnutrition in a cohort of older patients admitted with an acute disease to a general hospital. The American Journal of Clinical Malnutrition 2015; 34: 436-42.

18. Tufan A. Screening oropharyngeal dysphagia in hospitalized older adults. Marmara Medical Journal 2016; 29: 15256.

19. Mohamed E. The effectiveness of swallowing training program following 
cerebrovascular stroke. Unpublished Master Thesis, Faculty of Nursing, Alexandria University, 2006; 17.

20. Waleed A, Wael A, Abdel-Mateen M. Prevalence of Dysphagia among Patients at Sohag University Hospital, Southern District of Egypt. The Egyptian Journal of Neck Surgery and Otorhinolaryngology 2014; 1(2): 25-33.

21. Clavé P, Shaker R. Dysphagia: current reality and scope of the problem. Nature Clinical Practice Gastroenterology \&Hepatology 2015; 12: 259-70.

22. Williams P. Basic Geriatric Nursing. 5th ed. China: Elsevier CO, 2016; 124-28.

23. Norman A, Metheny R. Risk Factors for Aspiration. Journal of Parenteral and Enteral Nutrition 2016; 26(5): 526-33.

24. Bours R. Speyer J, Lemmens M, Limburg R. Bedside screening tests vs. videofluoroscopy or fibreoptic endoscopic evaluation of swallowing to detect dysphagia in patients with neurological disorders. The Journal of Advanced Nursing 2009; 65: 477-93.

25. Sandhaus M, Zalon D, Valenti F. Promoting Evidence-Based Dysphagia Assessment and Management by Nurses. Journal of Gerontological Nursing 2009; 35: 20-27.

26. Main university hospital. Medical Departments statistics 2016; from January to December

27. Trapl M, Enderle P, Nowotny M. Dysphagia bedside screening for acutestroke patients: The Gugging Swallowing screen. Stroke 2007; 38(11): 2948-52.

28. Mahoney I, Brthel D. Functional evaluation: The Barthel Index. Medical Journal 1965; 16(2):56-61.

29. Hallaj F. Activity Patterns of Residents in Elderly Homes. Unpublished Master
Thesis. Alexandria University, Faculty of Nursing, 2007.

30. Rofes L, Arreola V, Romea M. Pathophysiology of oropharyngeal dysphagia in the frail elderly. Journal of Neurogastroenterology and Motility 2010; 22:851-58.

31. Wirth R, Dziewas R, Bwck AM, Clave P. Oropharyngeal Dysphagia in Older Persons. Clinical Interventions in Aging Journal 2016; 11:189-208.

32. Wieseke A, Bantz D, Siktberg L. Assessment and Early Diagnosis of Dysphagia. Geriatric Nursing Journal 2008; 29(6):376-83.

33. Robbins J, Kays S, Mccallum S. Team Management of Dysphagia in the Institutional Setting. Journal of Nutrition for the Elderly 2007; 26(3):59-104.

34. Ney D, Weiss J, Kind A, Robbins J. Senescent swallowing: Impact, strategy and interventions. Nutrition in Clinical Practice Journal 2009; 24: 395-413.

35. Wakabayashi H, Matsushima M. Dysphagia Assessed by the10-Item Eating Assessment Tool is Associated with Nutritional Status and Activities of Daily Living in Elderly Individuals Requiring Long-Term Care. Journal of Nutrition Health and Aging 2016; 20:22-27.

36. Cabre M, Serra-Prat M, Force L, Almirall J, Palomera E, Clave P. Oropharyngeal Dysphagia is a Risk Factor for Readmission for Pneumonia in the Very Elderly Persons. Journal of Gerontology A Serious Biological Sciences 2014; 69:33037.

37. Sorensen RT, Rasmussen RS, Overgraad K. Dysphagia Screening and intensified Oral Hygiene Reduce Pneumonia after Stroke. Journal of Neuroscience Nursing 2013; 45(3):139-46. 
38. Michou E. Dysphagia and swallowing disorders. Nursing in practice Journal 2014; 29(1):140-47.

39. Kalf JG, Swart BJ, Bloem BR. Prevalence of Oropharyngeal Dysphagia in Parkinson's disease. Parkinsonism Related Disorder Journal 2012; 18(4):311-15.

40. Robinson DJ, Jerrard P, Greene Z. Oropharyngeal Dysphagia in Exacerbations of Chronic Obstructive Pulmonary Disease. European Geriatric Medicine Journal 2011; 2:201-3.

41. Fucile S, Wright PM, Chan I, Yee S, Langlais ME, Gisel EG. Functional oralmotor skills: Do they change with age? .Dysphagia Journal 2014; 13:195-201.

42. Wakabayashi H, Matsushima M, Uwano R, Watanabe N,Oritsu H, Shimizu Y. Skeletal Muscle Mass is Associated with Severe Dysphagia in Cancer Patients. Journal of Cachexia, Sarcopenia and Muscle 2015; 6:351-57.

43. Asadollahpour F, Baghban K, Asadi M, Naderifar E, Dehghan M. Oropharyngeal Dysphagia in Acute Stroke Patients. Journal of Research in Medical Sciences 2014; 17(8):34-36.

44. Gonzalez M, Ottenstein L, Atanelov L, Christian AB. Dysphagia after stroke. Current Physical Medicine and Rehabilitative Reports 2013; 1: 187-96.

45. Warncke T. Assessment of aspiration risk in acute ischemic stroke- evaluation of the simple swallowing provocation test. Journal of Neurosurgery and psychiatry 2014; 79:312-14.

46. Fusco S, Cariati D, Schepisi R, Ganzetti M, Sestili S, David L. Management of Oral Drug Therapy in Elderly Patients with Dysphagia. Journal of Gerontology and Geriatrics 2016; 64:9-20.
47. Campos R, Palma P, Leite I. Quality of life in patients with dysphagia after radiation and chemotherapy treatment for head and neck tumors. Journal of clinical and experimental dentistry 2013; 5(3): 122-27.

48. Kawais S, Yokota T, Onozawa Y, Hamauchi S, Fukutomi A, Ogawa H. Risk Factors for Aspiration Pneumonia after Definitive Chemoradiotherapy or Bioradiotherapy for Locally Advanced Head and Neck Cancer. Bio Medical Central Cancer 2017; 17:59-66.

49. Park S. Dysphagia Risk and Associated Factors Among Community-Dwelling Elders. Journal of the Korean Society of Food Science and Nutrition 2015; 44: 4956.

50. Logemann JA. Swallowing Disorders. Best Practice and Research Clinical Gastroenterology Journal 2007; 21: 56373.

51. Holland G, Jayasekeran V, Pendleton N. Prevalence and Symptom Profiling of Oropharyngeal Dysphagia in a Community Dwelling of an Elderly Population: a selfReporting Questionnaire Survey. Diseases of the Esophagus Journal 2011; 24: 47680 .

52. Nogueira D, Reis E .Swallowing Disorders in Nursing Home Residents. Clinical Intervention in Aging Journal 2013; 8: 221-27.

53. Michelle A, Poyne MA. Dysphagia: A New Geriatric Syndrome. Journal of the American Medical Directors Association 2017; 18(7): 555-57.

54. Byoen H. Analysis of Dysphagia Risk Using the Modified Dysphagia Risk Assessment for the Community-Dwelling Elderly. Journal of Physical Therapy Science 2016; 28(9): 2507-9. 
55. Clave P, Arreola V, Romea M. Accuracy of the Volume-Viscosity Swallow Test for Clinical screening of Oropharyngeal Dysphagia and Aspiration. Clinical Nutrition Journal 2008; 27(6):806-15.

56. Butler S, Stuart A. Factors Influencing Aspiration during Swallowing in Healthy Older Adults. Laryngoscope Journal 2013; 120(11):2147-52.

57. Ende F, Ickenstein G. Respiratory and Nutritional Complications in Oropharyngeal Dysphagia. Journal of Gastroenterology and Hepatology Research 2014; 3(10):200-56.

58. Palese A, LesaL,Stroppolo G, Lupieri G, Tardivo S, Brusaferro S. Factors Precipitating the Risk of Aspiration in Hospitalized Patients: Findings from a Multicentre Critical Incident Technique Study. International Journal for Quality in Health Care 2017; 29(2):194-99.

59. Whang SA. Prevalence and influencing Factors of Dysphagia Risk in the Community-Dwelling Elderly. Journal of the Korean Geriatrics Society 2014; 34: 37-48.

60. Hawash M. Assessment of Oral Health Status for the Residents of Elderly Homes. Unpublished Master Thesis, Faculty of Nursing, Alexandria University, 2006; 7879.
61. Huang S, Chiou C, Liu H. Risk Factors of Aspiration Pneumonia Related to Improper Oral Hygiene Behavior in Community Dysphagia Persons with Nasogastric Tube Feeding. Journal of Dental Science 2017; 12(4): 375-81.

62. Latino AM. Clinical Factors Predicting Risk for Aspiration and Respiratory Aspiration among Patients with Stroke. Americana Journal 2015; 23(2):216-24.

63. Heitkemper M, Jarrett M, Bond EF, Chang L. Impact of Sex and Gender on Irritable Bowel Syndrome. Biological Research for Nursing 2007; 5: 56-65.

64. Cabre M, Serra-prat M, PalmeraE,Almirall J, Pallares R, Clave P. Prevalence and Prognostic Implications of Dysphagia in Elderly Patients with Pneumonia. Age and Aging Journal 2010; 39:39-45.

65. Yang EJ, Kim MH, Lim JY, Paik NJ. Oropharyngeal Dysphagia in a Community-Based Elderly Cohort. Medical Science on Health and Aging Journal 2013; 28:1534-39.

66. Hafez S. Adherence with Medications for Diabetes Mellitus and Associated Factors among Older Adult Patients. Unpublished Master Thesis, Faculty of Nursing, Alexandria University, 2011; 64. 